\title{
Correspondence
}

\section{Psychiatric medications are no more effective}

Martin \& Elworthy report that the biggest reason for prescribing electroconvulsive therapy (ECT) less frequently than before is the perception among psychiatrists that 'more effective medication' now exists. ${ }^{1}$ Unfortunately, the authors collude with this exaggerated view, claiming that 'psychiatric medications have undoubtedly become more effective over recent years'. Their bold statement references a 2002 story in The New York Times.

Meta-analysis shows that the current first-line treatments for depressive disorder, selective serotonin reuptake inhibitors, are marginally less effective than older tricyclic antidepressants (TCAs), while serotonin-noradrenaline reuptake inhibitors show no statistically significant advantage over TCAs. ${ }^{2}$ One newer drug, reboxetine, does not work at all, yet is inexplicably still licensed as an antidepressant.

Lithium remains the only true mood stabiliser: it is the only drug with efficacy in treating acute manic and depressive symptoms and in prophylaxis of manic and depressive symptoms in bipolar disorder. ${ }^{4}$

One has to conclude that the prevailing delusion that treatments across psychiatry have become more effective has been mediated by the pharmaceutical industry. Psychiatrists should take their evidence from meta-analyses in peerreviewed journals, not from advertising representatives and certainly not from the newsstand.

1 Martin F, Elworthy T. Scottish psychiatrists' attitudes to electroconvulsive therapy: survey analysis. Psychiatrist 2013; 37: 261-6.

2 Machado M, Iskedjian M, Ruiza I, Einarson TR. Remission, dropouts, and adverse drug reaction rates in major depressive disorder: a meta-analysis of head-to-head trials. Curr Med Res Opin 2006; 22 1825-37.

3 Eyding D, Lelgemann M, Grouven U, Hrter M, Kromp M, Kaiser T, et al. Reboxetine for acute treatment of major depression: systematic review and meta-analysis of published and unpublished placebo and selective serotonin reuptake inhibitor controlled trials. BMJ 2010; 341: c4737.

4 Bauer MS, Mitchner L. What is a 'mood stabilizer'? An evidence-based response. Am J Psychiatry 2004; 161: 3-18.

Richard Braithwaite, Consultant Psychiatrist, Isle of Wight NHS Trust, email: richard.braithwaite@iow.nhs.uk

doi: $10.1192 / \mathrm{pb} .37 .12 .403$

Author response: Dr Braithwaite is correct in challenging the view that antidepressants have become more effective. Our study did show that this is a dominant view within the profession that may contribute to reduced ECT prescribing rates, and articles such as those referenced may help to perpetuate this view. We concede that our use of the general media to support this assertion reflects clumsy referencing on our part. There are, however, peer-reviewed studies that support the view of increased effectiveness of some newer antidepressants over some older antidepressants. ${ }^{1}$ This may in part be related to efficacy but also better tolerability, and pharmaceutical company influence could also be a factor. However, the perceived belief that new equates to better can easily be challenged and Dr Braithwaite's example of reboxetine is a good one.

1 Cipriani A, La Ferla T, Furukawa TA, Signoretti A, Nakagawa A, Churchill $R$, et al. Sertraline versus other antidepressive agents for depression. Cochrane Database Syst Rev 2009; 2: CD006117

Fiona Martin and Tim Elworthy, University of Dundee Medical School, Ninewells Hospital and Medical School, Dundee, UK, email: fiona.martin5@nhs.net

doi: 10.1192/pb.37.12.403a

\section{Psychiatry needs more psychotherapy}

I could not disagree more strongly with Michael Fitzgerald's letter ${ }^{1}$ asserting that all future psychiatrists should be neuropsychiatrists. Having worked as a medical psychotherapist for over 20 years, my job changed and I had a choice between resigning and becoming a community psychiatrist. I found instead that what many of my colleagues and particularly the junior doctors seemingly had difficulty with was precisely that lack of certainty, the need to listen with minute attention to what the patient was saying, which of course is the bedrock of psychotherapy. We need more, not less, psychotherapy to be embedded into psychiatry. We desperately need medical psychotherapists to act as role models for trainees or else we will lose the essence of our art - and yes, I use the word advisedly - and we will become glorified technicians. Is this really what we want?

1 Fitzgerald M. All future psychiatrists should be neuropsychiatrists. Psychiatrist 2013; 37: 309.

Teresa J. Black, Consultant Psychiatrist, Complex Care Team, Steps to Health, Black Country Partnership NHS Foundation Trust, Wolverhampton, email: Teresa.Black@bcpft.nhs.uk

doi: 10.1192/pb.37.12.403b

\section{Psychiatrists as neurologists . . . or biologists?}

Michael Fitzgerald thinks that 'All future psychiatrists should be neuropsychiatrists' 1 - and, what's more, should only concern themselves with diagnosis and prescribing, leaving psychological treatments to non-psychiatrists. I disagree. Don't get me wrong, I enjoy 'hunt the lesion' as much as anyone I know. And I have valued my medical school-level neurology on the few occasions when it has come in really handy. But to hive off all psychological interventions to other professions is where I take issue. Let us look at the two 'core' tasks Fitzgerald suggests and try to take the psychology out of them.

In spite of the golden dawn promised over the course of my career, there are still no physical investigations that usefully inform the most common issues of psychiatric diagnosis. The main instrument of investigation continues to be conversation. William Osler stated one of the fundamental principles in this area - 'Listen to your patient, he is telling you the diagnosis'. This sounds simple, but it clearly is not. The patient will only tell the doctor the necessary information if the patient feels that they are being taken seriously and listened to. ${ }^{2}$ Some of us 
are born listeners of this sort, most of us are not. It is a psychological skill that we can acquire - but, I have found, one that needs psychological understanding and training. So, diagnosis is not just about working through questionnaires and searching for physical signs, but about a more subtle and interactive process of building trust and establishing a clear dialogue.

What about prescription? The fact is that even if I aspire only to be a humble manipulator of neurochemicals and pharmaceuticals, psychology and culture keep getting in the way. Apparently straightforward conversations about pharmacological treatments are actually highly loaded psychological interactions which demand psychological skills to negotiate successfully. Which may be why adherence to medication is poor across all areas of medicine. ${ }^{3}$ And when you bear in mind the limited effectiveness of most biological treatments (again, not unlike the rest of medicine), the prescriber is burdened with the purely psychological task of supporting the patient through the difficult task of trying one drug (or combination) after another to achieve a worthwhile result.

So, the retreat to a biopharmacological bunker might be attractive to those who like the spurious certainty of diagnostic and treatment algorithms. It might suit others who prefer to focus on one domain rather than straddle several. However, it just won't work therapeutically. If you separate off psychological skills and social understanding from the training of psychiatrists, we will be training a generation of idiot savants, good only for delivering simplistic (and ever-changing) diagnostic labels, or for prescribing medications that their patients don't take.

1 Fitzgerald M. All future psychiatrists should be neuropsychiatrists. Psychiatrist 2013; 37: 309.

2 Ley P. Communicating with Patients: Improving Communication, Satisfaction and Compliance. Nelson Thornes, 1997.

3 Osterberg L, Blasche K. Adherence to medication. N Engl J Med 2009; 353: 487-97.

Philip Timms, Consultant Psychiatrist, South London and Maudsley NHS Foundation Trust, email: philip.timms@slam.nhs.uk

doi: $10.1192 / p b .37 .12 .403 \mathrm{c}$

\section{Some psychiatrists should continue to directly provide psychological therapies}

Fitzgerald ${ }^{1}$ suggests that psychiatrists should not directly provide psychological therapies. There are a number of reasons why some of them should.

First, specialist experience in delivering psychological therapies may strengthen the skill of a psychiatrist in choosing when and how to use psychopharmacology. A psychiatrist's experience in administering both psychotherapy and psychopharmacology may improve their ability to judge when to commence, combine or cease either treatment. ${ }^{2}$ Indeed, the New Ways of Working for Psychiatrists report ${ }^{3}$ predicted an increase in the need for support from consultant psychiatrists in psychotherapy for individuals with complex problems.
Second, some individuals may need difficult risk assessments while receiving psychotherapy. The different career path of a psychiatrist to that of a psychotherapist may make them better suited to make these assessments.

As for the financial cost of psychiatrists providing psychotherapy being 'prohibitive', Layard et al ${ }^{4}$ have argued that the implementation of NICE guidelines requiring psychological therapies may be self-financing when the effect of depression and anxiety disorders on the wider economy is taken into account.

1 Fitzgerald M. All future psychiatrists should be neuropsychiatrists. Psychiatrist 2013; 37: 309.

2 Royal College of Psychiatrists, Royal College of General Practitioners. Psychological Therapies in Psychiatry and Primary Care (College Report CR151). Royal College of Psychiatrists, 2008.

3 Department of Health. New Ways of Working for Psychiatrists: Enhancing Effective, Person-Centred Services through New Ways of Working in Multidisciplinary and Multi-Agency Contexts. Department of Health, 2005.

4 Bell S, Clark D, Knapp M, Layard R, Meacher MC, Priebe S, et al. The Depression Report: A New Deal for Depression and Anxiety Disorders. London School of Economics and Political Science, 2006.

Mohsin Khan, FY2 Doctor, Wycombe Hospital, email: mohsin.khan@ doctors.net.uk

doi: $10.1192 /$ pb.37.12.404

Author response: There is no need for professional concern about psychiatrists being largely neuropsychiatrists. The family factors, psychodynamic and sociological factors will still be acknowledged by the neuropsychiatrist but treatment of persons where these factors are relevant will be by non-medical professionals, psychotherapists, psychologists and social workers at a much lower financial cost. The neuropsychiatrist will still be team leader and have overall clinical responsibility.

Dr Black makes an interesting point. I may not have been clear enough in my original letter. I believe all consultant adult and child psychiatrists should be trained to about masters level in psychotherapy for the purpose of supervising junior staff in training. The actual face-to-face individual psychotherapy would be done by junior staff and non-medical staff.

Dr Timms mentions the psychiatrist's role in the 'interactive process of building trust and establishing a clear dialogue' with patients. I would have thought this was part of the role of all doctors, including all mental health professionals. Dr Khan writes about the Department of Health's view of the 'need for support from consultant psychiatrists in psychotherapy'. There is no doubt that psychotherapists with difficult patients need the support and second opinion of their consultant psychiatrist colleagues, especially with those patients who are not making progress because of missed diagnoses or not being on appropriate medication.

Michael Fitzgerald, Psychiatrist, Trinity College Dublin, Ireland, email: prof.m.fitzgerald@gmail.com

doi: 10.1192/pb.37.12.404a 